\title{
Padrões de liberação de urediniósporos e desenvolvimento da ferrugem do jambeiro(1)
}

\author{
Luiz Eduardo Bassay Blum ${ }^{(2)}$ e José Carmine Dianese ${ }^{(3)}$
}

Resumo - O objetivo deste trabalho foi avaliar padrões epidemiológicos de campo do fungo (Puccinia psidii Winter) que causa a ferrugem em jambeiro (Syzygium jambos). Entre 29/3 e 31/12/1988, levantou-se a incidência da doença e a população aérea de urediniósporos, na Universidade de Brasília, DF. Avaliaram-se dez plantas, sendo que, entre duas delas, instalou-se uma armadilha Burkard caça-esporos de sete dias. A maior quantidade de urediniósporos capturada foi de 23 de junho a 6 de julho. A principal carga de esporos ocorreu de maio a julho, entre as $10 \mathrm{~h}$ e as 13 horas. Os maiores números de brotos de jambeiro com pústulas esporulantes ocorreram entre 28 de abril e 20 de julho. O número de brotos terminais infectados foi positivamente correlacionado com a quantidade de esporos. A temperatura (às 12h) foi negativamente correlacionada com a quantidade de urediniósporos dispersos no ar. O número de dias com umidade relativa (UR) do ar (às $24 \mathrm{~h}$ ) $\geq 80 \%$ foi positivamente correlacionado com a quantidade de brotos deformados. A quantidade de urediniósporos foi positivamente correlacionada com o número de dias com temperatura $\leq 20^{\circ} \mathrm{C}$ e $\mathrm{UR}_{(24 h)} \geq 80 \%$. Ao maior pico de urediniósporos capturados precedeu um período sem precipitação, porém com vários dias de $\mathrm{UR}_{(24 \mathrm{~h})} \geq 80 \%$ e temperatura $\leq 20^{\circ} \mathrm{C}$. Estes dados mostraram que a doença foi favorecida por temperaturas $\leq 20^{\circ} \mathrm{C}$ e por UR noturna $\geq 80 \%$.

Termos para indexação: Puccinia psidii, Syzygium jambos, doenças das plantas, fatores ambientais.

\section{Patterns of urediniospores release and development of rose apple rust}

Abstract - This research was conducted to evaluate some epidemiological features of the rose apple (Syzygium jambos) rust (Puccinia psidii Winter) under field conditions at the Universidade de Brasília, Brasília, DF, Brazil, from March 29 through December 31, 1988. Data for the amount of airborne urediniospores were collected in ten plants, using a Burkard's seven-day volumetric spore trap set between two rose apple trees. Most of the airborne urediniospores were collected between June 23 and July 6, from 10 a.m. to 1 p.m. The major quantity of $S$. jambos affected shoots occurred between April 28 and July 20. There was a positive correlation between the amount of trapped urediniospores and infected young shoots. A negative correlation was shown between temperature (12h) and number of airborne urediniospores. The number of days with relative humidity $(\mathrm{RH}) \geq 80 \%$ was positively correlated to the amount of deformed shoots. Also, the amount of urediniospores and infected young shoots were positively correlated to the number of days with night $(24 \mathrm{~h})$ temperature $\leq 20^{\circ} \mathrm{C}$ or night $\mathrm{RH} \geq 80 \%$. These data show that this disease was favored by low temperatures $\left(\leq 20^{\circ} \mathrm{C}\right)$, high night $\mathrm{RH}(\geq 80 \%)$ and high levels of airborne urediniospores.

Index terms: Puccinia psidii, Syzygium jambos, plant diseases, environmental factors.

(1) Aceito para publicação em 6 de outubro de 2000

(2) Universidade do Estado de Santa Catarina, Centro de Ciências Agroveterinárias, Dep. de Fitotecnia, Caixa Postal 281, CEP 88520-000 Lages, SC. E-mail: a2lbb@cav.udesc.br

(3) Universidade de Brasília, Dep. de Fitopatologia, CEP 70910-000 Brasília, DF. E-mail: jcarmine@unb.br

\section{Introdução}

Em jambeiro (Syzygium jambos (L.) Alston) o fungo causador da ferrugem, Puccinia psidii Winter (Anamorfo: Caeoma eugeniarum Link) é comum nas regiões centrais e sul do Brasil. Este fungo afeta ou- 
tras mirtáceas, como: Abbevillea moschalanthe Berg, Callistemon speciosus DeCandolle, Campomanesia spp. Berg, Eucalyptus spp. L'Her, Eugenia spp. Berg, Feijoa sellowiana Berg, Marlierea edulis Niedenzu, Melaleuca spp. L., Myrciajaboticaba (Velloso) Berg, Myrciaria spp. Berg, Pimenta offcinalis L., Psidium guajava L., e outras espécies de Psidium L. (MacLachlan, 1938; Joffily, 1944; Hennen et al., 1982; Castro et al., 1983; Ferreira, 1983; Coutinho \& Figueiredo, 1984; Dianese et al., 1984, 1986; Ferrari et al., 1997; Rayachhetry et al., 1997). Em jambeiro e em outras plantas, as perdas causadas pela ferrugem podem ser elevadas (Moraes et al., 1982; Ferreira, 1989; Coutinho et al., 1998).

A característica principal da doença é a formação de pústulas alaranjadas sobre os órgãos afetados, que com o passar do tempo secam. A ação do patógeno sobre a planta provoca deformações nos órgãos aéreos (hastes, folhas, flores e frutos), afetando assim os diversos processos fitofisiológicos (Ferreira, 1989).

$\mathrm{O}$ entendimento dos fatores que afetam o desenvolvimento e a ocorrência desta enfermidade é essencial para o seu manejo. Em condições controladas, dados epidemiológicos relativos à ferrugem-dojambeiro são freqüentes (Ferreira, 1981; Castro et al., 1984; Figueiredo et al., 1984; Ruiz, 1988), todavia, dados de campo são escassos (Blum et al., 1989).

Em geral, longos períodos de molhamento foliar, temperaturas abaixo de $20^{\circ} \mathrm{C}$ e alta umidade relativa do ar favorecem a doença (Ferreira, 1989).

O objetivo deste trabalho foi avaliar a liberação aérea de urediniósporos, os danos provocados pela ferrugem, e os fatores ambientais que podem influenciar no desenvolvimento da doença.

\section{Material e Métodos}

Este estudo foi efetuado no campus da Universidade de Brasília (UnB), Brasília, DF, durante o ano de 1988. Utilizou-se uma armadilha caça-esporos de sete dias, da marca Burkard (Burkard Scientific Instruments, Rickmansworth, Herts., U.K.), colocada dentro de uma área cercada. Esta armadilha, colocada sobre uma plataforma de alvenaria a $70 \mathrm{~cm}$ do solo, situava-se a $3 \mathrm{~m}$ de duas árvores de jambeiro infectadas por Puccinia psidii. A armadilha (sucção de ar a $10 \mathrm{~L} / \mathrm{min}$ ) continha um tambor, que girava a uma velocidade de $2 \mathrm{~mm} / \mathrm{h}$, com fita adesiva (Melinex com Gelvatol a 10\% - $35 \mathrm{~g}$ de gelvatolBurkard Scientific; $100 \mathrm{~mL}$ de água destilada; $50 \mathrm{~mL}$ de glicerol; $2 \mathrm{~g}$ de fenol) colocada ao seu redor para a captura dos urediniósporos. A fita adesiva ajustada ao tambor da armadilha era substituída semanalmente. A leitura diária e horária do número de urediniósporos capturados foi feita a cada sete dias, mediante a montagem de sete lâminas para microscopia - uma para cada dia da semana -, com um pedaço de $48 \mathrm{~mm}$ de fita adesiva por lâmina. Em cada $2 \mathrm{~mm}$ da fita ( 1 hora de coleta), foi observado, ao microscópio óptico, o número de urediniósporos de P. psidii, registrado a cada hora. Este método e o preparo da fita adesiva foram descritos em detalhes por Santos et al. (1986).

Dados sobre a quantidade (máximo de 100 para cada $1 / 3$ da planta $-1 / 3$ inferior, $1 / 3$ médio e $1 / 3$ superior) de brotos novos de jambeiro afetados e brotos secos foram coletados a cada 14 dias, com início em 29 de março e término em 18 de outubro de 1988 (total de 14 períodos), de dez plantas previamente selecionadas e marcadas; dentre estas dez plantas estavam as duas próximas à armadilha. Neste intervalo de tempo foram avaliados o número de brotos afetados, médias de temperatura e de umidade relativa do ar (UR) às 12 e $24 \mathrm{~h}$, número de urediniósporos acumulados, número de dias com UR às $24 \mathrm{~h}$, maior ou igual a $80 \%$, e número de dias com temperatura menor ou igual a $20^{\circ} \mathrm{C}$ às 24 horas.

Os dados meteorológicos (Figuras 1 e 2) foram obtidos no local do experimento (período de orvalho, UR e temperatura), no Instituto Nacional de Meteorologia (UR e temperatura às 24h), e no Posto Meteorológico da Estação Experimental de Biologia da UnB, Brasília, DF (precipitação pluvial). O molhamento foliar foi medido por um sensor elétrico em forma de folha, colocado em uma das árvores próxima à armadilha. Este aparelho basicamente compunha-se de um circuito elétrico em forma de folha, que, quando fechado pela formação de orvalho, emitia um sinal elétrico até um registrador de sinais, com papel para registro horário. Neste registrador ficavam impressos os horários de formação do orvalho. Este sensor trabalhou adequadamente no período de 28 de junho a 8 de agosto (Figura 1), dia em que foi levantado o número de casos e os valores de temperatura e UR registrando-se a de formação de orvalho entre as 0 e $8 \mathrm{~h}$ da manhã. Os dados obtidos pelo sensor durante este período foram utilizados para se obter indiretamente, através da UR e da temperatura, os períodos noturnos (entre as 0 e $8 \mathrm{~h}$ ), com formação de molhamento (orvalho) foliar para aqueles períodos de avaliação onde o sensor não foi utilizado.

Análises de regressão e de variância $(\mathrm{P}=0,05)$ foram executadas quando possível e quando apresentavam algu- 
ma possível significância biológica. Também foram feitas análises de correlação entre os dados obtidos, mas foram apresentadas apenas as correlações com significância $(\mathrm{P}=0,05)$ estatística ou com significado biológico lógico.

\section{Resultados e Discussão}

A formação de orvalho é um dos fatores determinantes de novas infecções e produção de novos urediniósporos de Puccinia psidii. Nas avaliações foi possível detectar a formação de orvalho a partir de UR, igual ou superior a $80 \%$, e temperaturas iguais ou inferiores a $20^{\circ} \mathrm{C}$ (Figura 1 ). Ao contrário, alguns autores informam que a formação de orvalho ocorre apenas quando a UR é igual ou superior a $90 \%$ (Ferreira, 1983; Ruiz, 1988) e a temperatura abaixo de $20^{\circ} \mathrm{C}$ (Ferreira, 1989). Salienta-se que essas condições (orvalho, temperaturas menores que

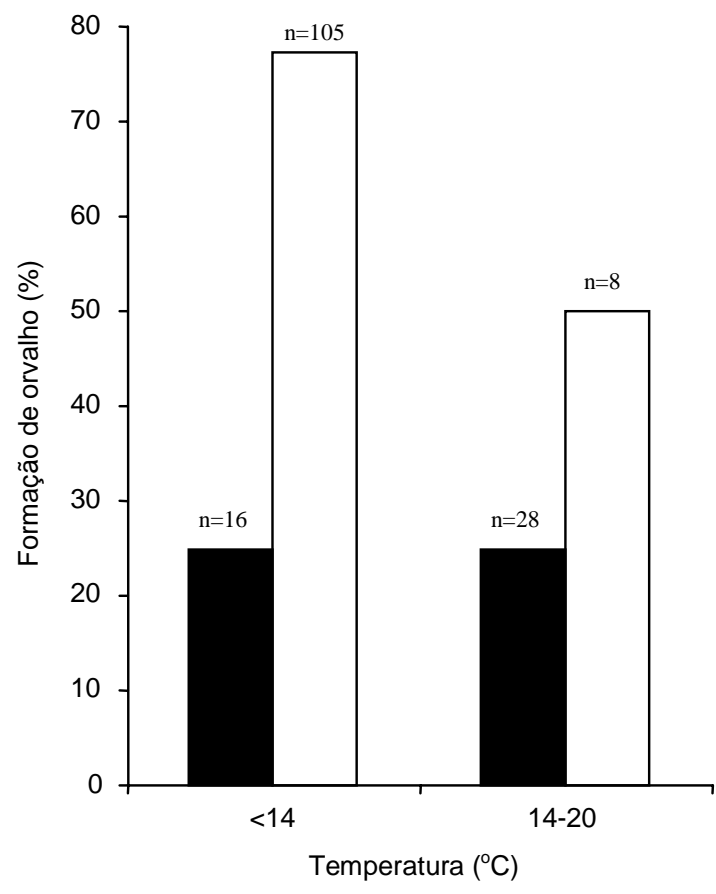

UR $80-89,9 \% \quad \square$ UR $90-100 \%$

Figura 1. Porcentagem de casos com formação de orvalho (n: número total de casos com formação de orvalho) entre as 0 e $8 \mathrm{~h}$ da manhã no período de 28 de junho a 8 de agosto de 1988 , em razão da temperatura e da umidade relativa do ar (UR).
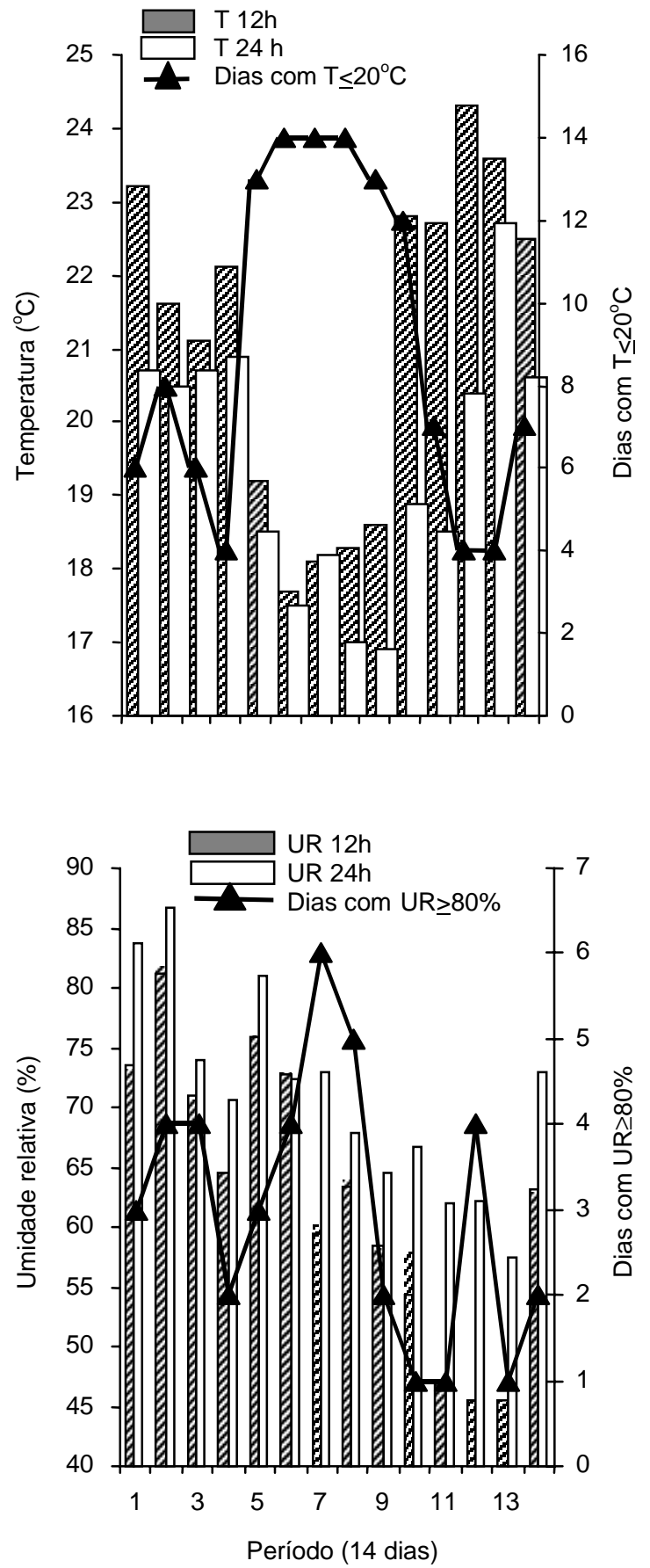

Figura 2. Temperatura (T) e umidade relativa do ar (UR) média às $12 \mathrm{~h}$ e $24 \mathrm{~h}$ e número de dias com temperatura $\mathrm{e}$ UR às $24 \mathrm{~h} \leq 20^{\circ} \mathrm{C}$ e $\geq 80 \%$, respectivamente, em cada um dos 14 períodos. 
$20^{\circ} \mathrm{C}$ e alta UR) são necessárias à germinação, penetração e infecção do fungo. Durante o período do estudo estas condições ocorreram (Figuras 2 e 3 ) e coincidiram com índices mais elevados de esporos produzidos e com o aumento da doença (Figuras 3 e 4).

A época de maior captura de esporos ocorreu no período 7, entre 23 de junho e 6 de julho, embora uma quantidade razoável de esporos tenha sido detectada a partir de 12 de maio no período 4 (Figura 3). Verificou-se, também, que os dois grandes picos na captura de esporos, entre 12 e 25 de maio (período 4) e entre 23 de junho e 6 de julho (período 7), foram precedidos de períodos longos com condições de temperatura e UR favoráveis à produção de urediniósporos (Figura 2). Ferreira (1983) comenta que períodos de duas a três semanas com dias de temperatura relativamente baixas e alta umidade podem favorecer a ocorrência de surtos da ferrugem.
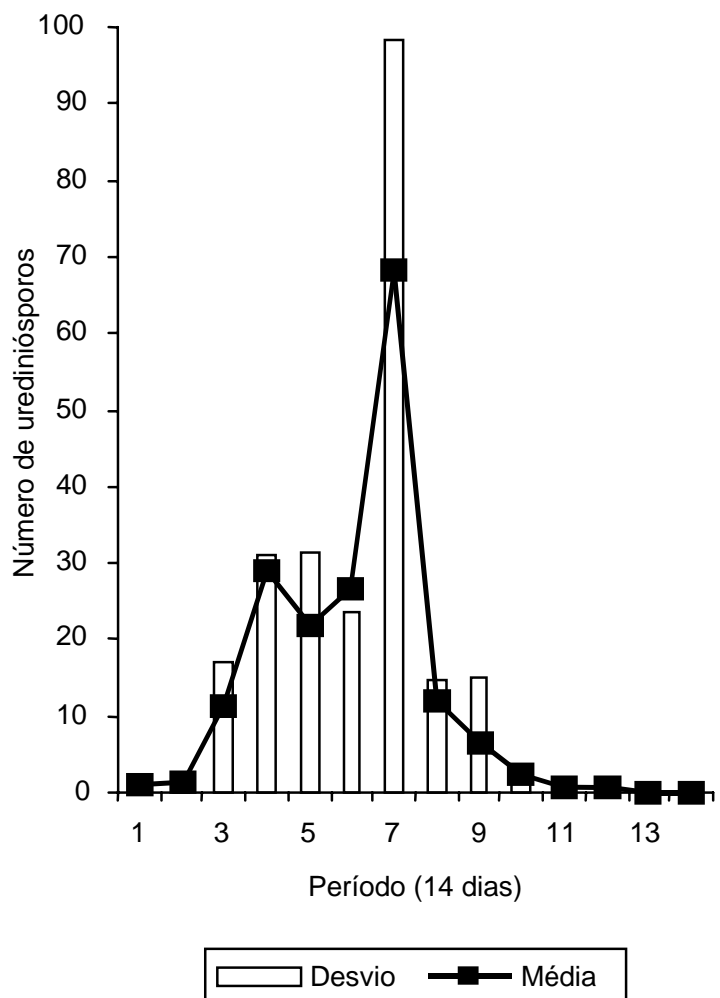

Figura 3. Médias diárias e desvio padrão do número de urediniósporos capturados em cada período. (DMS $=39,43$; Tukey, $\mathrm{P}=0,05$; média relativa a 14 repetições.)
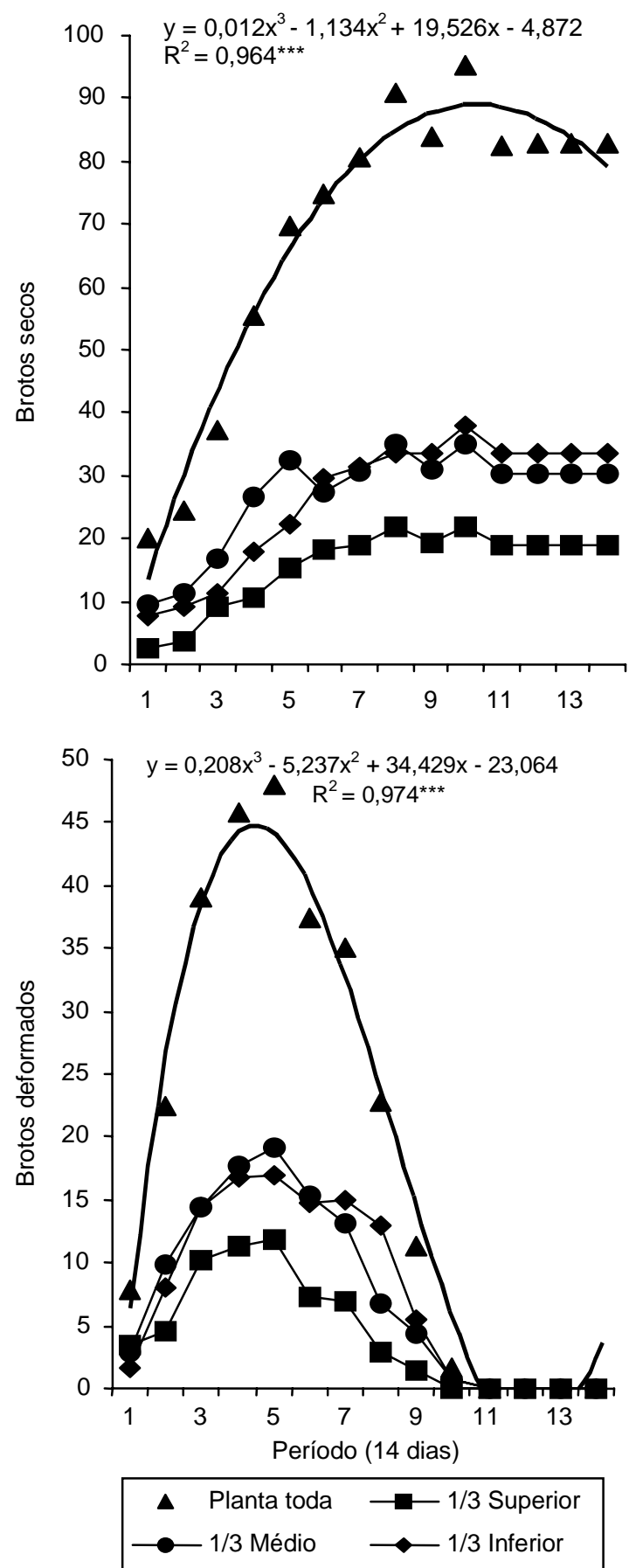

Figura 4. Número médio de brotos secos e deformados e esporulantes na planta toda e nos terços superior, médio e inferior da planta. $(* * *$ Regressão significante a $\mathrm{P}=0,001$; média relativa a dez repetições.) 
Uma queda na detecção de urediniósporos foi verificada entre 26 de maio e 8 de junho (período 5), no qual ocorreram três dias com precipitação, o que pode ter prejudicado o fluxo aéreo de esporos, e, em conseqüência, a sua captura pela armadilha. Períodos onde a UR às $24 \mathrm{~h}$ foi igual ou superior a $80 \%$, propiciaram entre cinco a sete horas de molhamento foliar, em face da formação de orvalho. Após 21 de julho (período 8), verificou-se uma queda na captura de esporos (Figura 4), número de dias com $\mathrm{UR} \geq 80 \%$ (Figura 3 ), e com temperatura $\leq 20^{\circ} \mathrm{C}$ (Figura 2), brotos com pústulas urediniospóricas (regressão polinomial significativa de terceira ordem) esporulantes e uma estabilização no número de brotos secos (regressão polinomial significativa de terceira ordem), devido à ferrugem (Figura 4). Esta constatação pode ser justificada parcialmente pelos relatos de Ferreira (1989), relativos às condições favoráveis e desfavoráveis à ferrugem, bem como, por Ruiz (1988), que verificou que temperaturas superiores a $20^{\circ} \mathrm{C}$ e períodos pouco propícios à formação de orvalho noturno dificultam a produção de urediniósporos e também de novos sítios de infecção.

Houve uma correlação positiva e estatisticamente significativa entre o número total de urediniósporos do período, e o número de brotos afetados não-secos $(\mathrm{r}=0,670 ; \mathrm{P}=0,01)$, número de dias com temperatura inferior a $20^{\circ} \mathrm{C}$ às $12 \mathrm{~h}(\mathrm{r}=0,633 ; \mathrm{P}=0,05)$, número de dias com UR maior que $80 \%$ às $24 \mathrm{~h}$ $(\mathrm{r}=0,590 ; \mathrm{P}=0,05)$ e com o número de dias com temperatura inferior a $20^{\circ} \mathrm{C}$ e UR superior a $80 \%$ $(\mathrm{r}=0,769 ; \mathrm{P}=0,05)$ (Tabela 1$)$. A correlação foi negativa e estatisticamente significativa quando se associou o número de urediniósporos com a média de temperatura do período às $12 \mathrm{~h}(\mathrm{r}=-0,628$; $\mathrm{P}=0,05)$. O número de brotos afetados foi positivamente relacionado $(\mathrm{r}=0,542 ; \mathrm{P}=0,05)$ ao número de dias com UR superior a $80 \%$ e temperatura infe- rior $\mathrm{a} 20^{\circ} \mathrm{C}$ às $24 \mathrm{~h}$ e negativamente $(\mathrm{r}=0,628 ; \mathrm{P}=0,05)$ relacionado com a temperatura às 12 horas. Estes resultados em condições de campo assemelham-se, e confirmam os relatos em condições controladas de Ruiz (1988) e de Ferreira (1989).

De maneira geral, o mês em que mais se detectaram urediniósporos e brotos afetados foi o de junho (Figura 5). A faixa horária de maior captura de esporos foi entre $9 \mathrm{~h}$ e $15 \mathrm{~h}$; a maior parte foi verificada entre as $10 \mathrm{~h}$ e 13 horas. Estas faixas de maior captura de esporos coincidem com as menores UR do dia, significando que os mesmos não estariam aderidos

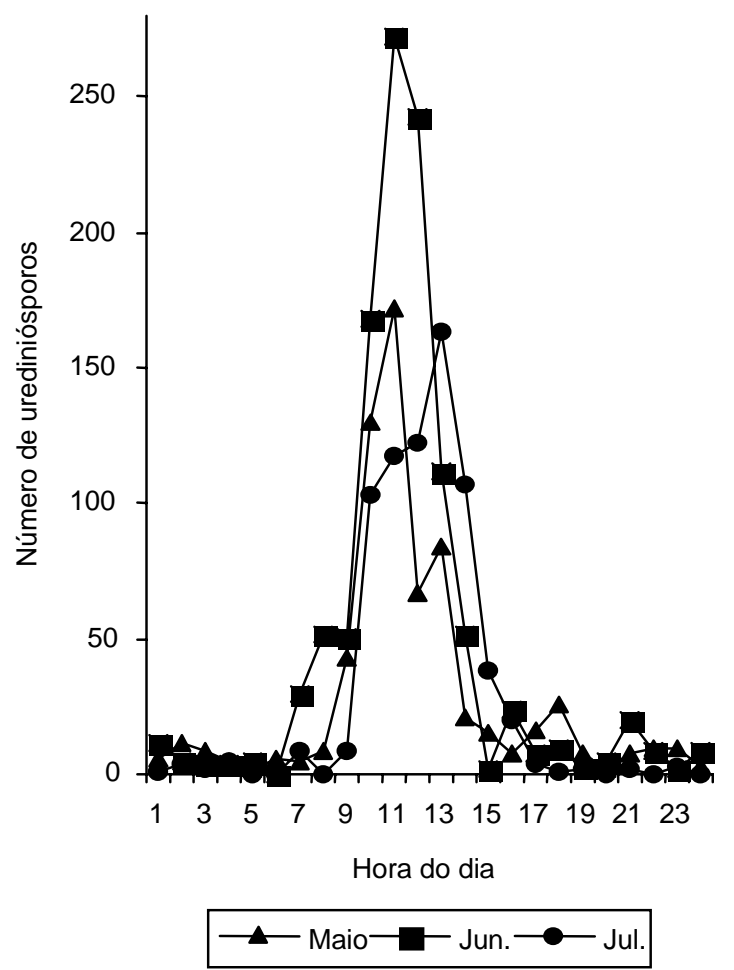

Figura 5. Número total de urediniósporos capturados nos meses de maio, junho e julho em razão da hora do dia.

Tabela 1. Coeficientes de correlação de Pearson entre dados ambientais, número de brotos deformados e de urediniósporos capturados em jambeiro ${ }^{(1)}$.

\begin{tabular}{lccccc}
\hline Variável & Temperatura $\left({ }^{\circ} \mathrm{C}\right)_{12 \mathrm{~h}}$ & \multicolumn{2}{c}{ Número de dias do período com as condições de: } & \multirow{2}{*}{ Esporo } \\
\cline { 3 - 5 } & & $\mathrm{T} \leq 20^{\circ} \mathrm{C}_{12 \mathrm{~h}}$ & $\mathrm{UR} \geq 80 \%_{24 \mathrm{~h}}$ & $\leq 20^{\circ} \mathrm{C}_{12 \mathrm{~h}} / \geq 80 \%_{24 \mathrm{~h}}$ & \\
\hline Broto & $-0,628^{*}$ & $\mathrm{~ns}$ & $\mathrm{~ns}$ & $0,542^{*}$ & $0,670^{* *}$ \\
Esporo & $-0,628^{*}$ & $0,633^{*}$ & $0,590^{*}$ & $0,769 * *$ & - \\
\hline
\end{tabular}

${ }^{(1)}$ T: temperatura às $12 \mathrm{~h}$; UR: Umidade relativa do ar às 24 horas. ns Não-significativo. * e **Significativo a 5\% e a $1 \%$ de probabilidade, respectivamente. 
entre si pela umidade, e que estariam sujeitos à disseminação eólica.

\section{Conclusões}

1. O número de urediniósporos capturados é maior de maio a julho, entre $10 \mathrm{~h}$ e $13 \mathrm{~h}$, e correlaciona-se positivamente com o número de brotos de jambeiro afetados.

2. Em condições de campo, temperatura menor ou igual a $20^{\circ} \mathrm{C}$, longos períodos com molhamento foliar e umidade relativa noturna $\geq 80 \%$, favorecem a ferrugem do jambeiro.

\section{Referências}

BLUM, L. E. B.; DIANESE, J. C.; MIRANDA, A. C. Epidemiology of the rust of Syzygium jambos in Brasília. Fitopatologia Brasileira, Brasília, v. 14, n. 2, p. 140, 1989.

CASTRO, H. A.; BERGAMIN FILHO, A.; KRUGNER, T. L. Padrão de produção de uredósporos em mudas de Eucalyptus spp. inoculadas artificialmente com Puccinia psidii. Summa Phytopathologica, Jaboticabal, v. 10, n. 1, p. 155-170, 1984.

CASTRO, H. A.; KRUGNER, T. L.; IDERILHA, C. H. F.; CAPELLO, M. S.; MARCHI, A. B. Inoculação cruzada de Eucalyptus, goiaba (Psidium guajava) e jambeiro (Syzygium jambos) com Puccinia psidii. Fitopatologia Brasileira, Brasília, v. 8, n. 3, p. 491-497, 1983.

COUTINHO, L. N.; FIGUEIREDO, M. B. Estudos sobre especializações fisiológicas em Puccinia psidii. Summa Phytopathologica, Jaboticabal, v. 10, n. 1, p. 56-57, 1984.

COUTINHO, T. A.; WINGFIELD, M. J.; ALFENAS, A. C.; CROUS, P. W. Eucalyptus rust: a disease with the potential for serious international implications. Plant Disease, St. Paul, v. 82, n. 7, p. 819-825, 1998.

DIANESE, J. C.; HARIDASAN, M.; MORAES, T. S. A. Screening Eucalyptus species for rust resistance in Bahia, Brazil. Tropical Pest Management, London, v. 32, p. 292$295,1986$.

DIANESE, J. C.; MORAES, T. S. A.; SILVA, R. A. Response of Eucalyptus species to field infection by Puccinia psidii. Plant Disease, St. Paul, v. 68, n. 4, p. 314316, 1984.
FERRARI, J. T.; NOGUEIRA, E. M. C.; SANTOS, A. J. T. Control of rust (Puccinia psidii) in guava (Psidium guajava). Acta Horticulturae, Leuven, n. 452, p. 55-57, 1997.

FERREIRA, F. A. Ferrugem do eucalipto: ocorrências, temperatura para germinação de uredósporos, produção de teliósporos, hospedeiro alternativo e resistência. Fitopatologia Brasileira, Brasília, v. 6, n. 3, p. 603-604, 1981.

FERREIRA, F. A. Ferrugem do eucalipto. Revista Árvore, Viçosa, v. 7, n. 2, p. 23-27, 1983.

FERREIRA, F. A. Patologia florestal: principais doenças florestais no Brasil. Viçosa : Sociedade Brasileira de Investigações Florestais, 1989. 570 p.

FIGUEIREDO, M. B.; COUTINHO, L. N.; HENNEN, J. F. Estudos para determinação do ciclo vital de Puccinia psidii. Summa Phytopathologica, Jaboticabal, v. 10, n. 1, p. 53-54, 1984.

HENNEN, J. F.; HENNEN, M. M.; FIGUEIREDO, M. B. Índice das ferrugens (Uredinales) do Brasil - Puccinia psidii. Arquivos do Instituto Biológico, São Paulo, v. 49, n. 1, p. 84-86, 1982. Suplemento.

JOFFILY, J. Ferrugem do eucalipto. Bragantia, Campinas, v. 4, n. 8, p. 475-487, 1944.

MacLACHLAN, J. D. A rust of the pimento tree in Jamaica, B. W. I. Phytopathology, St. Paul, v. 28, n. 8, p. 157-170, 1938.

MORAES, T. S. A.; GONÇALVES, E. L.; REZENDE, G. C.; MENDES, C. J.; SUITER FILHO, W. Evolução da ferrugem causada pela Puccinia psidii em Eucalyptus spp. Piracicaba : Instituto de Pesquisas e Estudos Florestais, 1982. 12 p. (Circular técnica, 144).

RAYACHHETRY, M. B.; ELLIOT, M. L.; VAN, T. K. Natural epiphytotic of the rust Puccinia psidii on Melaleuca quinquenervia in Florida. Plant Disease, St. Paul, v. 81, n. 7, p. 831, 1997.

RUIZ, R. A. R. Epidemiologia e controle químico da ferrugem (Puccinia psidii Winter) do eucalipto. Viçosa : UFV, 1988. 108 p. Dissertação de Mestrado.

SANTOS, J. R.; DIANESE, J. C.; ANJOS, J. R. N.; NASSER, L. C. B. Aerobiologia de Puccinia graminis e P. recondita no Distrito Federal. Fitopatologia Brasileira, Brasília, v. 11, n. 3, p. 581-586, 1986. 